\title{
The Impact of Diabetes on Workforce Participation: Results from a National Household Sample
}

\author{
Sandeep Vijan, Rodney A. Hayward, and Kenneth M. Langa
}

Objective. Diabetes is a highly prevalent condition that results in substantial morbidity and premature mortality. We investigated how diabetes-associated mortality, disability, early retirement, and work absenteeism impacts workforce participation.

Data Source. We used the Health and Retirement Study (HRS), a national household sample of adults aged 51-61 in 1992, as a data source.

Study Design. We conducted cross-sectional analyses on the baseline HRS data, and longitudinal analyses using data from eight years of follow-up. We used two-part regression models to estimate the adjusted impact of diabetes on workforce participation, and then estimated the economic impact of diabetes-related losses in productivity.

Principal Findings. Diabetes is a significant predictor of lost productivity. The incremental lost income due to diabetes by 1992 was $\$ 60.0$ billion over an average diabetes duration of 9.7 years. From 1992 to 2000, diabetes was responsible for $\$ 4.4$ billion in lost income due to early retirement, $\$ 0.5$ billion due to increased sick days, $\$ 31.7$ billion due to disability, and $\$ 22.0$ billion in lost income due to premature mortality, for a total of $\$ 58.6$ billion dollars in lost productivity, or $\$ 7.3$ billion per year.

Conclusions. In the U.S. population of adults born between 1931 and 1941, diabetes is associated with a profound negative impact on economic productivity. By 1992, an estimated $\$ 60$ billion in lost productivity was associated with diabetes; additional annual losses averaged $\$ 7.3$ billion over the next eight years, totaling about $\$ 120$ billion by the year 2000. Given the rising prevalence of diabetes, these costs are likely to increase substantially unless countered by better public health or medical interventions.

Key Words. Disability, chronic disease, health economics

\section{BACKGROUND}

Diabetes has staggering health and economic effects. There are an estimated 16-17 million people with diabetes in the United States (Centers for Disease Control and Prevention 2002) and, given the aging of the population, changes in ethnic makeup, and the dramatic increase in obesity and sedentary lifestyles in the United States, the prevalence of diabetes is increasing at an epidemic rate (Boyle et al. 2001). In 1997, a cross-sectional analysis found that the direct 
medical cost of diabetes care was more than $\$ 44$ billion (American Diabetes Association 1998). However, the effects of lost productivity have been felt to be even more substantial (American Diabetes Association 1998).

The indirect costs of diabetes are largely related to the disability resulting from complications of the disease, rather than to the disease itself. Microvascular diabetes complications, such as retinopathy, nephropathy, and neuropathy, are the leading causes of blindness, end-stage renal disease, and nontraumatic amputation, respectively, in the United States (National Institutes of Health 1995). Even more important is macrovascular disease (including coronary artery disease, stroke, and peripheral vascular disease). Patients with diabetes have two to four times the risk of macrovascular disease and mortality compared to age and sex-matched controls; as a result, more than 70 percent of patients with diabetes die from these complications (Abbott et al. 1987; deGrauw et al. 1995; deMarco R et al. 1999; Donahue and Orchard 1992; Hadden et al. 1997).

Although the numbers of disabling diabetes complications are staggering, many are preventable, and appropriate therapy could lead to substantial reductions in complications and associated disability. However, the true economic impact of diabetes remains unclear. While there are a number of past studies of the costs of diabetes, these analyses have substantial limitations and often reach widely disparate conclusions because of differences in data sources and methodology. For example, these studies have been forced to look at indirect costs by compiling data from multiple sources, have had nonrepresentative data sources, or have not examined the economic impact of all diabetes-related disabilities (American Diabetes Association 1998; Gregg et al. 2000; Ramsey et al. 2002; Gregg et al. 2002). To date, no studies have been able to use a consistent or representative data source to identify the impact of diabetes on workforce participation. Understanding the economic impact of diabetes on workforce-related outcomes allows a more complete understand-

Supported by Social Security Administration/Michigan Retirement Research Center grant UM01-11. Dr. Vijan is also supported by a Veterans Affairs Career Development Award, and Dr. Langa by a National Institute on Aging Career Development Award (K08 AG19180), and an Alzheimer's Association New Investigator Research Grant.

Address correspondence to Sandeep Vijan, M.D., M.S., VA HSR\&D, 2215 Fuller Road, 11H, Ann Arbor, MI 48105. Dr. Vijan, Rodney A. Hayward, M.D., and Kenneth M. Langa, M.D., Ph.D., are with the Veterans Affairs Center for Practice Management \& Outcomes Research, Ann Arbor, MI, and the Department of Internal Medicine. Additionally, Drs. Vijan and Hayward are with the Michigan Diabetes Research and Training Center, and Dr. Langa is with the Institute for Social Research, University of Michigan. 
ing of the cost-effectiveness of diabetes treatment programs, and may provide a rationale for employers to begin to address workplace programs to improve health.

Using the Health and Retirement Study (HRS), we analyzed the effects of diabetes on workforce participation and lost productivity. The HRS is a longitudinal survey designed to follow a national sample of U.S. adults born between 1931 and 1941 (and their spouses) as they make the transition from active working status into retirement. The HRS provides an excellent opportunity to overcome limitations with prior studies and to better estimate the impact of diabetes on economic productivity.

\section{Methods}

Data

The HRS is a national longitudinal cohort study that is funded by the National Institute on Aging and is conducted by the Institute for Social Research at the University of Michigan (Juster and Suzman 1995). Approximately 70,000 households, obtained from an area probability sample, were screened to identify all age-eligible respondents (51 to 61 years of age). The HRS is a nationally representative survey of households, not of individuals. For example, if a spouse is outside of the age range specified in the study, they were still included in the dataset; therefore, the complete HRS dataset is not a perfectly representative sample of those 51 to 61 years of age at the time of the study. Thus, we restricted our analyses to the age-eligible population in the HRS.

Census tracts containing a high density of African Americans and Florida residents were oversampled two to one. All spouses were interviewed regardless of age because of the frequency of dual-earner couples and the influence of spouses in the retirement decision. The overall response rate was 82 percent. Information was collected for domains including demographics, health status, housing, family structure, employment, work history, disability, retirement plans, net worth, income, and health and life insurance. To date, five waves of data collection have been completed; the first was in 1992, and the ensuing four waves were collected at two-year intervals through 2000 (Health and Retirement Study 2003).

\section{Variables}

Classification of Outcome Variables: Work Status and Duration. The HRS has detailed information on the work status of the study participants. For the 
cross-sectional analyses using wave 1 data, we subdivided the population into those who were and were not working outside the home. Those who were working outside the home were asked whether they missed work days in the prior year due to illness, and if so, the total number of days. Subjects who were not currently working were subdivided into those who reported being retired, those who reported being disabled, and those who were homemakers. Of note, there are different possible definitions of disability; we examined both those with self-reported overall disability and also those who were not working specifically due to a health condition, although we used self-reported disability in our main analyses. Dates of retirement and disability were used to determine the duration of each outcome. In the case of those disabled at baseline, we also projected their future lost income through the year 2000 in a separate analysis. This analysis took into account the reported rates of returning to work among those disabled at baseline.

In wave 1 , some subjects claimed to be retired but still working (12.7 percent of the retired). For the main analyses, these subjects were included as retired, although we conducted sensitivity analyses excluding these respondents. In the case of disability, 1.8 percent of those who claimed to be disabled also claimed to be working; we therefore conducted a sensitivity analysis using those who reported a specific health impairment limiting work.

In the longitudinal analyses of waves $2-5$, the work status questions in the HRS (e.g., working, disabled, retired) were reconfigured to be mutually exclusive. The goal of the longitudinal analysis was to identify incident cases of disability, retirement, and mortality among those working at the prior wave; thus, for each wave, the number of subjects "eligible" for an outcome was determined based on their status in the prior wave. For example, those who claimed to be disabled at baseline were not included in subsequent analyses of disability (unless they claimed to be not disabled in a future wave, in which case they became eligible to become disabled again). The duration of disability and retirement was calculated based upon the total amount of time spent in the states until the year 2000; we did not project future lost income beyond this point. We also estimated the impact of early mortality on lost productivity. Mortality in the HRS sample from 1992 to 2000 was reported in December 2002 (Health and Retirement Study 2002). We crossreferenced the HRS data with data from the National Death Index and found the mortality reports to be accurate in 97 percent of cases in the first two waves. As with disability, retirement, and sick days, we calculated lost productivity for mortality through the year 2000 . 
Classification of Diabetes Mellitus Status. All respondents were asked: "Have you ever had diabetes?" If a respondent answered "yes," he or she was assumed to be diabetic. A follow-up question also asked if the subject was currently diabetic; fewer subjects reported having diabetes now than ever having diabetes. For the sake of this analysis, we used the first question to define diabetes. This may include patients with glucose intolerance, medication-induced diabetes, or gestational diabetes; however, as these groups also have elevated risks of complications, particularly cardiovascular disease (Alberti 1996; Wingard et al. 1993; Lindeman et al. 1998), we elected to include them as part of the overall population with diabetes.

Demographic Variables. The sociodemographic measures included in the analysis as independent variables were age, gender, living situation (unmarried living alone, unmarried living with others, married), level of education (grade school, high school, college, graduate school), and race (white, African American, Hispanic, Asian, other). White and Hispanic are mutually exclusive in the dataset. We did not include income as a covariate since those who were disabled at baseline did not report income in wave 1. To calculate lost income, we estimated annual income in several ways. For the cross-sectional analysis, we used the median reported income of the working population in the HRS in 1992 (a conservative approach compared to using mean income). For the longitudinal analysis, we used the actual reported income in 1992 as the baseline value. For homemakers, we used an average reported income of $\$ 43$ per day in 1997 dollars; this was adjusted to 1992 dollars using present value calculations (American Diabetes Association 1998). All income was discounted at 3 percent per annum for present value calculations in future waves beyond 1992 .

\section{General Analysis Plan}

The analyses were done in two stages. In the first stage, to estimate the impact of diabetes on workforce participation prior to the recruitment of the cohort, we conducted cross-sectional analyses of wave 1 (1992) of the HRS data. This analysis is retrospective and includes historical information, based on recall, about diabetes status and disability status, allowing estimation of the economic impact of diabetes in this cohort through 1992. In the second stage of the analyses, we examined the impact of diabetes on incident changes in workforce status prospectively over the next four biennial waves of the HRS, from 1994 to 2000. In this analysis, only those subjects who had been diagnosed with diabetes by wave 1 of the HRS were defined as having diabetes; thus, 
incident cases of diabetes were not included in the calculations. This leads to conservative estimates of rates of disability, since our analyses omit potential cohort members who died from diabetes-related complications prior to 1992 and also omits the 5.2 percent of the cohort who developed new diabetes over the eight years of follow up of the HRS (of whom between 20 and 30 percent reported being disabled). Further, those disabled at baseline were excluded from analyses of incident disability. However, to examine this factor, we conducted separate analyses of those disabled at baseline to estimate their continued losses through the year 2000. Thus, the cohort was born 1931-1941, and was followed beginning in 1992. Our retrospective analyses track productivity losses due to three outcomes (disability, retirement, and absenteeism) prior to 1992, but cannot include mortality since the cohort had not yet been established for study. From 1992 to 2000, we tracked prospective losses due to these three outcomes plus mortality after 1992, but did not include the effects of those who developed incident diabetes during those eight years. A general description of the cohort in shown in Figure 1.

\section{Analyses}

All analyses were done using survey weights to account for complex survey design (Juster and Suzman 1995; The Health and Retirement Study 2003). Analyses were conducted using Stata Version 8.0 (Stata Corporation 2003).

For the cross-sectional analyses, our main outcome measures were work absenteeism, retirement, and disability. The longitudinal analyses included these outcomes and also mortality; we conducted these analyses wave by wave in order to allow estimation of incident cases of each outcome. In both cases, because a substantial proportion of respondents did not have the outcome, and the distribution of duration among those who did was skewed, we analyzed the data using a two-part multivariable model (Duan et al. 1983). We first used logistic regression to estimate the association of diabetes with each of the workforce outcomes, while controlling for demographics. In the second part, we used linear ordinary least squares (OLS) regression to examine the association of diabetes with the natural logarithm of the duration of each outcome in those who had the outcome (e.g., the duration of disability in those who were disabled), again controlling for demographics. The results from each part of the model were then combined to obtain an estimate of the unconditional (not conditioned on having the outcome) effect of diabetes on each outcome. Regression results were then retransformed back into natural units using a smearing estimator (Manning 1998). 
Figure 1: Study Timeline and Cohort Descriptions

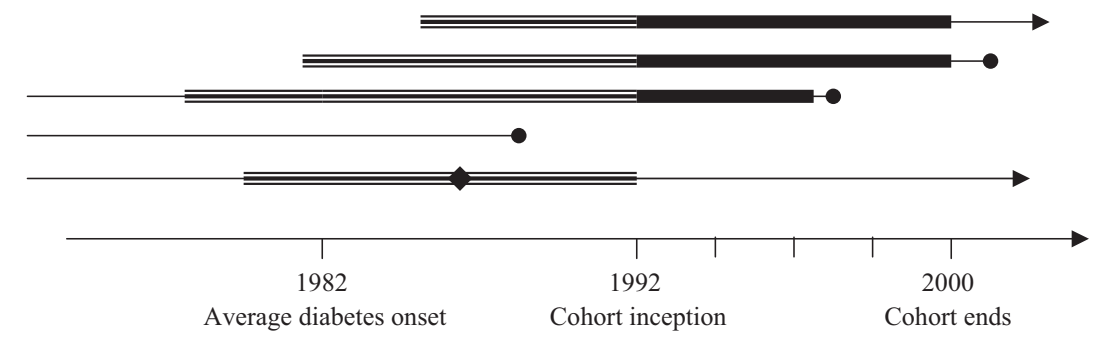

\begin{tabular}{l}
\hline \hline Retrospective analysis of productivity losses associated with di- \\
abetes. The cohort includes all study subjects alive in 1992, and the \\
analysis examines retrospectively the diabetes-associated incremental \\
losses in productivity due to disability, sick time, and early retirement. \\
Prospective analysis of productivity losses associated with dia- \\
betes. This cohort is a subset of the retrospective cohort, including \\
only those who were working at cohort inception (1992), and exclud- \\
ing from the diabetes cohort those who had new diagnoses of diabetes \\
made after cohort inception. The analyses examine prospectively, \\
from 1992-2000, the diabetes-associated incremental losses in pro- \\
ductivity due to disability, sick time, early retirement, and mortality. \\
Closed circle indicates date of death; arrow indicates subject is alive. \\
People with only a "thin line" are not included in either analysis and \\
include two major groups: those who died prior to 1992 and those \\
who developed diabetes after 1992. \\
Diamond indicates the date at which someone with diabetes drops out \\
of the labor force. These people are included in the retrospective \\
study (as long as they are still alive in 1992) but are not included in the \\
prospective studies.
\end{tabular}

The economic impact of diabetes was then estimated by multiplying income times the estimated incremental change in productivity predicted by the models. For the cross-sectional analyses, we used the median income of the working cohort, while for longitudinal analyses, we used reported income at wave 1 of the HRS. The exception to this rule was for those who considered themselves homemakers; in this group, we applied the homemaker's wage. 
In most cases in both longitudinal and cross-sectional analyses we had direct reports on duration of outcomes. However, in the cross-sectional analyses of sick time, we only had reports on the prior year; in order to estimate total impact over the duration of diabetes, we assumed that the incremental effect of diabetes was constant over the duration of diabetes (an average of 9.7 years) and applied the lost productivity estimates to this entire period. We tested this assumption by examining the association between diabetes duration and sick time; in this sample, we found no association between the two. Further, to project losses through the year 2000 in the cohort of subjects disabled at baseline, we imputed the likelihood of working in future waves based upon their demographic characteristics. We then adjusted the estimates of time lost from work by the probability that the subjects would have continued to work. In those who were projected to work, we assigned the median income value, while in those who were projected not to work, we assigned the homemaker's wage (American Diabetes Association 1998).

In the case of mortality, we estimated productive time lost by projecting forward from the time of death through the year 2000 (wave 5 of the study). As with disability, we adjusted the lost productivity for mortality by using the imputed probability that subjects would have continued to work if they had remained alive. In those projected to work, we assigned the baseline reported income value to those projected to work, while in those who were projected not to work, we assigned the homemaker's wage.

To provide national estimates of lost income, the results from each analysis were then projected to the U.S. population for those born between 1931 and 1941 based on the survey-weighted population estimates in the HRS (Juster and Suzman 1995; Health and Retirement Study 2003).

\section{RESULTS}

\section{Descriptive Statistics}

Table 1 shows the characteristics for the HRS population with and without diabetes. The weighted prevalence (to achieve nationally representative estimates) of diabetes in this 1931 to 1941 U.S. birth cohort was 9.9 percent, which translates to about 2.3 million people in the U.S. population. This prevalence is similar to other prevalence estimates of diabetes in this age group (Harris 1990; Harris et al. 1998). The population with diabetes was slightly older, more likely to be male, more likely to be African American or Hispanic, and less educated than those without diabetes. Not surprisingly, those with 
Table 1: Characteristics of Health and Retirement Study Population at Baseline (1992)*

\begin{tabular}{|c|c|c|}
\hline & Population without Diabetes & Population with Diabetes \\
\hline \multicolumn{3}{|l|}{ Demographic Characteristics } \\
\hline Estimated population size (U.S.) & $23,587,252$ & $2,335,715$ \\
\hline Age (years) & 56.0 & 56.5 \\
\hline \multicolumn{3}{|l|}{ Gender } \\
\hline Male & $47.7 \%$ & $49.5 \%$ \\
\hline Female & $52.3 \%$ & $50.5 \%$ \\
\hline \multicolumn{3}{|l|}{ Race } \\
\hline White & $82.3 \%$ & $70.7 \%$ \\
\hline Black & $9.0 \%$ & $17.3 \%$ \\
\hline Hispanic & $5.7 \%$ & $8.9 \%$ \\
\hline Asian & $1.4 \%$ & $1.5 \%$ \\
\hline Other & $1.0 \%$ & $1.6 \%$ \\
\hline \multicolumn{3}{|l|}{ Educational Level } \\
\hline Grade school & $10.3 \%$ & $17.4 \%$ \\
\hline High school & $56.3 \%$ & $57.0 \%$ \\
\hline College & $21.4 \%$ & $17.8 \%$ \\
\hline Graduate school & $11.9 \%$ & $7.9 \%$ \\
\hline \multicolumn{3}{|l|}{ Health Status Characteristics } \\
\hline Coronary artery disease & $7.4 \%$ & $17.5 \%$ \\
\hline Congestive heart failure & $1.5 \%$ & $5.6 \%$ \\
\hline Stroke & $2.6 \%$ & $6.2 \%$ \\
\hline \multicolumn{3}{|l|}{ Visual acuity } \\
\hline Good & $88.9 \%$ & $78.8 \%$ \\
\hline Fair & $8.5 \%$ & $14.4 \%$ \\
\hline Poor & $2.6 \%$ & $6.8 \%$ \\
\hline Kidney or bladder problems & $10.2 \%$ & $19.2 \%$ \\
\hline Hypertension & $38.0 \%$ & $63.3 \%$ \\
\hline \multicolumn{3}{|l|}{ Smoking } \\
\hline Never & $35.9 \%$ & $32.2 \%$ \\
\hline Former & $37.1 \%$ & $43.3 \%$ \\
\hline Current & $27.0 \%$ & $24.5 \%$ \\
\hline
\end{tabular}

*The HRS study population included a nationally representative sample of adults aged 51 to 61 in 1992 .

diabetes reported substantially higher rates of comorbidities that are known to be associated with diabetes; they had much higher rates of coronary heart disease, congestive heart failure, stroke, visual impairment, kidney/bladder problems, foot problems, and hypertension than those without diabetes. General self-rated health status was also substantially worse in patients with diabetes than in those without diabetes (data not shown).

Table 2 shows the unadjusted weighted proportions and means of the workforce-specific characteristics of the population with and without diabetes 
Table 2: Work-Status Characteristics of Subjects with and without Diabetes at Baseline (1992)

\begin{tabular}{lccr}
\hline Work-Status Characteristic & $\begin{array}{c}\text { Population without } \\
\text { Diabetes }\end{array}$ & $\begin{array}{c}\text { Population with } \\
\text { Diabetes }\end{array}$ & $\begin{array}{c}\text { P-Value for } \\
\text { Comparison }\end{array}$ \\
\hline Sick days, prior year & 4.0 days & 6.6 days & 0.005 \\
Probability of retirement & $9.0 \%$ & $12.0 \%$ & 0.010 \\
Retirement age & 52.5 years & 51.3 years & 0.100 \\
Probability of self-rated disability & $7.5 \%$ & $22.9 \%$ & $<0.001$ \\
Duration of disability & 9.0 years & 8.5 years & 0.363 \\
Not working due to health impairment & $7.3 \%$ & $19.2 \%$ & $<0.001$ \\
$\begin{array}{l}\text { Duration of not working due to } \\
\text { health impairment }\end{array}$ & 8.2 years & 7.6 years & 0.263 \\
& & & \\
\hline
\end{tabular}

at baseline. Subjects with diabetes have substantially higher rates of work absence, disability, and probability of being retired than those without diabetes. However, among those who had retired or were disabled, subjects with diabetes did not retire earlier or have longer duration of disability than those without diabetes.

\section{Probabilities and Duration of Being in Different Workforce States}

The logistic regression models of the baseline data (cross-sectional analysis) showed that, after adjusting for differences in demographics, subjects with diabetes were substantially more likely than those without diabetes to be disabled (adjusted OR 3.1; 95 percent CI 2.6, 3.7), retired (adjusted OR 1.3; 95 percent CI 1.0, 1.7), or to have taken sick days in the prior year (adjusted OR 1.3; 95 percent CI 1.1, 1.7). However, the duration of these states, estimated using linear OLS regression was not substantially different between those with and without diabetes, with the exception of the number of sick days (1.2 more days; 95 percent CI 1.0-1.5 days). At the initiation of the HRS, the two-part model predictions show that subjects with diabetes had retired, on average, 0.12 years earlier than those without, had 0.66 more sick days in the prior year, and spent 0.99 more years disabled than those without diabetes (Table 3a).

The longitudinal analyses showed that the odds of outcomes were similarly higher for those with diabetes in each wave. For example, in those who were not disabled in the immediately preceding wave, those with diabetes were much more likely to become disabled by wave 2 (OR $2.8 ; 95$ percent CI 2.1, 3.7), wave 3 (OR 2.1; 95 percent CI 1.5, 2.9), wave 4 (OR 2.3; 95 percent CI 1.5, 3.5), or wave 5 (OR 2.8; 95 percent CI 2.0, 3.9). Indeed, the adjusted cumulative risk of incident disability over 8 years in subjects with diabetes was 
Table 3: Predicted Duration of Workforce Outcomes

a. The Impact of Diabetes on Workforce Participation through Inception of the Cohort (the U.S. Population Who Were Ages 51-61 in 1992) ${ }^{\dagger}$

\begin{tabular}{lccc}
\hline Workforce Characteristic & $\begin{array}{c}\text { Adjusted Duration, } \\
\text { Diabetes (95\% CI)* }\end{array}$ & $\begin{array}{c}\text { Adjusted Duration, } \\
\text { No Diabetes (95\% CI)* }\end{array}$ & $\begin{array}{c}\text { Incremental } \\
\text { Duration* }\end{array}$ \\
\hline Retirement & 0.62 years & 0.50 years & 0.12 years \\
Sick days, prior year & $(0.61,0.64)$ & $(0.49,0.51)$ & \\
& 4.8 days & 4.14 days & 0.66 days \\
Self-reported disability & $(4.75,4.85)$ & $(4.1,4.2)$ & \\
& 1.68 years & 0.69 years & 0.99 years \\
Not working due to health-related & $(1.61,1.76)$ & $(0.63,0.71)$ & \\
work impairment & 1.32 years & 0.62 years & 0.70 years \\
& $(1.27,1.37)$ & $(0.59,0.64)$ & \\
\hline
\end{tabular}

b. Cumulative Impact of Diabetes on Workforce Participation over Eight Years of Follow-up (1992-2000)

\begin{tabular}{lccc}
\hline Workforce Characteristic & $\begin{array}{c}\text { Adjusted Duration, } \\
\text { Diabetes (95\% CI)* }\end{array}$ & $\begin{array}{c}\text { Adjusted Duration, } \\
\text { No Diabetes }(95 \% \text { CI)* }\end{array}$ & $\begin{array}{c}\text { Incremental } \\
\text { Duration* }\end{array}$ \\
\hline Retirement & 2.82 years & 2.68 years & 0.14 years \\
Sick days & $(2.77,2.86)$ & $(2.64,2.72)$ & \\
Self-reported disability & 21.5 days & 19.1 days & 2.4 days \\
& $(21.3,21.8)$ & $(18.9,19.3)$ & \\
Mortality & 1.43 years & 0.64 years & 0.79 years \\
& $(1.37,1.50)$ & $(0.61,0.67)$ & \\
& 0.79 years & 0.25 years & 0.54 years \\
& $(0.77,0.81$ years) & $(0.25,0.25)$ & \\
\end{tabular}

*The adjusted duration is the prediction of the average duration of the outcome in all subjects, based on the estimates from the two-part regression model; these are adjusted for demographic status.

23.1 percent versus 9.3 percent in those without diabetes, and the adjusted total risk of any disability, including those disabled at baseline, was 39.3 percent in those with diabetes versus 15.7 percent in those without diabetes. However, as with the cross-sectional data, the average duration of each outcome was not different between those with and without diabetes. Table $3 \mathrm{~b}$ shows the estimates of the total and incremental time spent in each state in the longitudinal data; the reported times are cumulative over the eight-year follow-up period. During this eight-year follow-up, subjects with diabetes spent an incremental 0.14 years retired, had 2.4 more sick days, were disabled for 0.79 more years, and lost an average 0.54 more years of life. 


\section{Economic Impact}

Table 4 shows the estimated economic impact of the workforce participation losses associated with diabetes. Table 4a shows the impact that diabetes had already generated by wave 1 of the HRS. The average subject with diabetes had lost an incremental $\$ 2,800$ in wages due to early retirement, $\$ 630$ due to more sick days, and $\$ 22,100$ due to disability. Extending these results to the U.S. population born between 1931 and 1941 translates into incremental losses of $\$ 6.5$ billion due to early retirement, $\$ 1.5$ billion in excess sick days (assuming that sick time was constant over the average 9.7 year duration of diabetes), and $\$ 52.0$ billion due to disability. The total incremental loss of income was thus already $\$ 60$ billion at the inception of this cohort, or approximately $\$ 6.2$ billion per year. Because our longitudinal analyses excluded those disabled at baseline, their costs are not included in the analyses through

Table 4: Estimated Economic Impact of Diabetes*

a. The Economic Impact of Diabetes through Inception of the Cohort (the U.S. Population Who Were Ages 51-61 in 1992 ${ }^{\dagger}$

\begin{tabular}{lcr}
\hline Workforce Characteristic & $\begin{array}{c}\text { Average Incremental } \\
\text { Cost per Subject } \\
\text { with Diabetes }\end{array}$ & $\begin{array}{c}\text { Incremental Cost, } \\
\text { U.S. Population } \\
\text { with Diabetes }\end{array}$ \\
\hline Retirement & $\$ 2,800$ & $\$ 6.5$ billion \\
Sick days & $\$ 630$ & $\$ 1.5$ billion \\
Self-reported disability & $\$ 22,100$ & $\$ 52.0$ billion \\
Total & $\$ 25,530$ & $\$ 60.0$ billion
\end{tabular}

b. Cumulative Economic Impact of Diabetes in the Cohort over Eight Years of Follow-up (1992-2000)

\begin{tabular}{lcc}
\hline Workforce Characteristic & $\begin{array}{c}\text { Average Incremental } \\
\text { Cost per Subject } \\
\text { with Diabetes }\end{array}$ & $\begin{array}{c}\text { Incremental Cost, } \\
\text { U.S. Population } \\
\text { with Diabetes }\end{array}$ \\
\hline Retirement & $\$ 4,100$ & $\$ 4.4$ billion \\
Sick days & $\$ 550$ & $\$ 0.5$ billion \\
Self-reported disability & $\$ 19,500$ & $\$ 31.7$ billion \\
Mortality & $\$ 10,080$ & $\$ 22.0$ billion \\
Total & $\$ 34,230$ & $\$ 58.6$ billion \\
\hline
\end{tabular}

All costs are in 1992 dollars, and are discounted at 3\% per annum; costs are incremental versus those without diabetes.

The cohort was followed starting in 1992; thus, Table 4 a includes only lost productivity costs at baseline, and does not include prior mortality. 
year 2000; separate analyses of subjects who were disabled at baseline suggests an additional $\$ 14.9$ billion in lost income by the year 2000 for this group. Thus, those with diabetes who were disabled in $1992 \mathrm{had}$ a total of $\$ 74.9$ billion in lost productivity from the disability onset through the year 2000 .

Table $4 \mathrm{~b}$ shows the lost productivity due to incident cases of changes in workforce participation over the eight years of the HRS. Subjects with diabetes lost an incremental average of $\$ 4,100$ in income due to early retirement, $\$ 550$ due to increased sick days, $\$ 19,500$ due to disability, and $\$ 10,080$ due to early mortality compared to those without diabetes. The total lost income over eight years (1992-2000), extended to the U.S. diabetes population born between 1931 and 1941, is $\$ 58.6$ billion, or $\$ 7.3$ billion per year.

\section{DISCUSSION}

Diabetes is well known to be a major cause of medical morbidity and premature mortality. The morbidity associated with diabetes ranges from visual impairment to amputation to coronary heart disease, and is often disabling (National Institutes of Health 1995). Although previous work has suggested that societal costs from diabetes complications are substantial, we sought to better quantify the impact of diabetes on workforce participation, and to obtain national cost estimates for diabetes-related work loss.

As in prior studies, we found a very high economic cost associated with diabetes. A report based on a national sample of data collected in 1986 suggested that diabetes was responsible for about 950,000 cases of total disability and $\$ 8.2$ billion in lost productivity due to mortality and disability (Huse et al. 1989). In 1997, according to American Diabetes Association estimates, the indirect costs of diabetes totaled \$54 billion dollars (American Diabetes Association 1998). However, this figure was not estimated over a consistent timeframe; rather, it included both 1997 lost productivity estimates and future estimates due to increased mortality. We sought to estimate, using a single data source and a consistent time frame, the costs associated with lost productivity in the living cohort of patients with diabetes.

We found that in the U.S. cohort of people aged 51 to 61 years old in 1992 who had diabetes, the total loss in income due to health-related work impairment was already an incremental $\$ 60.0$ billion compared to those without diabetes. Over the ensuing eight years, the diabetes-related increase in incident risk of disability, mortality, sick days, and retirement led to an incremental $\$ 58.6$ billion in lost productivity, with $\$ 31.7$ billion due to disability 
and $\$ 22.0$ billion due to premature mortality. In addition, those who were already disabled at baseline lost another $\$ 14.9$ billion in productivity. Thus, the total lost productivity in this segment (those aged 51 to 61 years in 1992) of the U.S. cohort of people with diabetes was $\$ 133.5$ billion by the year 2000 , an average of $\$ 7.5$ billion per year (based on an average diabetes duration of 9.7 years prior to 1992). There are certain to be losses beyond the year 2000, although these will decline over time as a higher proportion of this cohort leaves the workforce due to retirement.

Our results are limited to the 1931-1941 U.S. birth cohort and are therefore not representative of all people with diabetes in the United States, making the cost estimates even more impressive. While this cohort did represent the major at-risk group at the time the survey data were collected, changing patterns in the incidence of diabetes portend a very concerning trend. Indeed, there is a marked rise in the incidence of diabetes, and the Centers for Disease Control has recently estimated that given current trends, one in three people born today will develop diabetes (McConnaghey 2003). Of particular concern is the rapid increase in diabetes in younger people. Given that those with younger diabetes onset will bear a disproportionate burden of complications and will have these complications at an early age (Vijan, Hofer, and Hayward 1997; CDC Diabetes Cost-effectiveness Group 2002), the losses in workforce participation from diabetes are likely to grow to staggering numbers unless the epidemic can be controlled.

There are several other limitations to these analyses. The major limitations relate to the use of cross-sectional data in the first part of the analysis. Recall bias is clearly an issue, and may adversely affect our estimates; however, as there are data suggesting that health conditions are "telescoped," that is, felt to have occurred sooner than they actually did, this makes it more likely that we have underestimated the economic impact of diabetes (Barsky 2002; Gaskell, Wright, and O'Muircheartaigh 2000). Further, recall problems could lead to difficulties in accurately estimating whether disability or diabetes came first. In the disabled with diabetes, the average duration of diabetes was longer than the average duration of disability, but in about one-third of patients, disability appears to precede the onset of diabetes. Estimating the directionality is made even more difficult because diabetes onset generally occurs from 4 to 10 years prior to diagnosis, and pre-diabetes, which carries substantial cardiovascular risk, is rarely diagnosed clinically (Harris et al. 1992). However, our longitudinal analyses help to answer some of these questions; the odds of adverse workforce outcomes are, as expected, lower than in the crosssectional data, though not by large amounts (e.g., the OR for disability in those 
with diabetes at baseline was 3.1, while it was 2.8 for incident cases by wave 2). In addition, the longitudinal analyses are more likely to underestimate the effects due to misclassification of undiagnosed diabetes. Another limitation imposed by the cross-sectional nature of this portion of the analysis is that we cannot estimate the impact of mortality on lost productivity. While we address this in the longitudinal analyses, the cross-sectional estimates cannot address this issue. Since diabetes increases the risk of cardiovascular mortality by twoto three-fold, we certainly underestimate the impact of diabetes on economic productivity (Abbott et al. 1987; deGrauw et al. 1995; deMarco et al. 1999; Donahue and Orchard 1992; Hadden et al. 1997).

The economic impact of diabetes on economic productivity in the United States is substantial and is likely to worsen substantially as the prevalence of diabetes increases, particularly in the young, over the next several decades. However, because many diabetes complications are preventable, there is hope that some of this economic impact can be attenuated with improved delivery of key components of diabetes care. Perhaps even more can be accomplished by public health intervention to prevent or reduce diabetes through increased physical activity, improved diet, and reduced obesity (Knowler et al. 2002). Further, since many of our estimates of lost productivity directly bear on employers, novel workplace programs targeting employee health may prove to be economically beneficial. For example, employers could offer exercise programs in the workplace, provide and encourage healthy food choices for employees, or support disease management programs, all of which can reduce long-term risks of diabetes and its complications. Our analyses suggest that such programs are likely to recoup substantial economic gains; indeed, economic analyses of diabetes treatment programs should explicitly consider these individual and societal costs, and policymakers and others who allocate public health and health care resources should be aware of the potential cost savings of improving diabetes treatment programs.

\section{REFERENCES}

Abbott, R. D., R. P. Donahue, S. W. MacMahon, D. M. Reed, and K. Yano. 1987. "Diabetes and the Risk of Stroke: The Honolulu Heart Program." Journal of the American Medical Association 257 (7): 949-52.

Alberti, K. G. 1996. "The Clinical Implications of Impaired Glucose Tolerance." Diabetic Medicine 13 (11): 927-37.

American Diabetes Association. 1998. "Economic Consequences of Diabetes Mellitus in the U.S. in 1997: American Diabetes Association." Diabetes Care 21 (2): 296-309. 
Barsky, A. J. 2002. "Forgetting, Fabricating, and Telescoping: The Instability of the Medical History." Archives of Internal Medicine 162 (9): 981-4.

Boyle, J. P., A. A. Honeycutt, K. M. Narayan, T. J. Hoerger, L. S. Geiss, H. Chen, and T. J. Thompson. 2001. "Projection of Diabetes Burden through 2050: Impact of Changing Demography and Disease Prevalence in the U.S." Diabetes Care 24 (11): 1936-40.

CDC Diabetes Cost-effectiveness Group. 2002. "Cost-effectiveness of Intensive Glycemic Control, Intensified Hypertension Control, and Serum Cholesterol Level Reduction for Type 2 Diabetes." Journal of the American Medical Association 287 (19): 2542-51.

Centers for Disease Control and Prevention. 2002. National Diabetes Fact Sheet: General Information and National Estimates on Diabetes in the United States, 2000. Atlanta: U.S. Department of Health and Human Services, Centers for Disease Control and Prevention.

deGrauw, W. J., E. H. van de Lisdonk, H. J. van den Hoogen, and C. van Weel. 1995. "Cardiovascular Morbidity and Mortality in Type 2 Diabetic Patients: A 22-Year Historical Cohort Study in Dutch General Practice.” Diabetic Medicine 12 (2): 117-22.

deMarco, R., F. Locatelli, G. Zoppini, G. Verlato, E. Bonora, and M. Muggeo. 1999. "Cause-Specific Mortality in Type 2 Diabetes: The Verona Diabetes Study." Diabetes Care 22 (5): 756-61.

Donahue, R. P., and T. J. Orchard. 1992. "Diabetes Mellitus and Macrovascular Complications: An Epidemiological Perspective." Diabetes Care 15 (9): 1141-55.

Duan, N., W. G. Manning, C. N. Morris, and J. P. Newhouse. 1983. "A Comparison of Alternative Models for the Demand for Medical Care." Journal of Business and Economic Statistics 1 (2): 115-26.

Gaskell, G. D., D. B. Wright, and C. A. O'Muircheartaigh. 2000. "Telescoping of Landmark Events: Implications for Survey Research.” Public Opinion Quarterly 64 (1): 77-89.

Gregg, E. W., G. L. A. Beckles, D. F. Williamson, S. G. Leveiller, J. A. Langlois, M. M. Engelgau, and K. M. Venkat Narayan. 2000. "Diabetes and Physical Disability among Older U.S. Adults.” Diabetes Care 23 (9): 1272-7.

Gregg, E. W., C. M. Mangione, J. A. Cauley, T. J. Thompson, A. V. Schwartz, K. E. Ensrud, and M. C. Nevitt. 2002. "Diabetes and Incidence of Functional Disability in Older Women." Diabetes Care 25 (1): 61-7.

Hadden, D. R., C. C. Patterson, A. B. Atkinson, L. Kennedy, P. M. Bell, D. R. McCance, and J. A. Weaver. 1997. "Macrovascular Disease and Hyperglycaemia: 10-Year Survival Analysis in Type 2 Diabetes Mellitus: The Belfast Diet Study." Diabetic Medicine 14 (8): 663-72.

Harris, M. I. 1990. "Epidemiology of Diabetes Mellitus among the Elderly in the United States." Clinics in Geriatric Medicine 6 (4): 703-19.

Harris, M. I., K. M. Flegal, C. C. Cowie, M. S. Eberhardt, D. E. Goldstein, R. R. Little, H. M. Wiedmeyer, and D. D. Byrd-Holt. 1998. "Prevalence of Diabetes, Impaired Fasting Glucose, and Impaired Glucose Tolerance in U.S. Adults: The 
Third National Health and Nutrition Examination Survey, 1988-1994.” Diabetes Care 21 (4): 518-24.

Harris, M. I., R. Klein, T. A. Welborn, and M. W. Knuiman. 1992. "Onset of NIDDM Occurs at Least 4-7 Years before Clinical Diagnosis.” Diabetes Care 15 (7): 815-9. Health and Retirement Study. 2002. "Tracker File Version 3.0" [accessed on December 21, 2002]. Available at http://hrsonline.isr.umich.edu/meta/tracker/desc/ track030.pdf.

— 2003. "The Health and Retirement Study" [accessed on March 10, 2003]. Available at http://hrsonline.isr.umich.edu.

Huse, D. M., G. Oster, A. R., M. J. Lacey, and G. A. Colditz. 1989. "The Economic Costs of Non-Insulin-Dependent Diabetes Mellitus." Journal of the American Medical Association 262 (19): 2708-13.

Juster, F. T., and R. Suzman. 1995. "An Overview of the Health and Retirement Study." Journal of Human Resources 30 (supplement): S7-56.

Knowler, W. C., E. Barrett-Connor, S. E. Fowler, R. F. Hamman, J. M. Lachin, E. A. Walker, and D. M. Nathan. 2002. "Reduction in the Incidence of Type 2 Diabetes with Lifestyle Intervention or Metformin." New England Journal of Medicine 346 (6): 393-403.

Lindeman, R. D., L. J. Romero, R. Hundley, A. S. Allen, H. C. Liang, R. N. Baumgartner, K. M. Koehler, D. S. Schade, and P. J. Garry. 1998. "Prevalences of Type 2 Diabetes, the Insulin Resistance Syndrome, and Coronary Heart Disease in an Elderly, Biethnic Population.” Diabetes Care 21 (6): 959-66.

Manning, W. G. 1998. "The Logged Dependent Variable, Heteroscedasticity, and the Retransformation Problem." Journal of Health Economics 17 (3): 283-95.

McConnaghey, J. 2003. "CDC Issues Diabetes Warning for Children." Washington Post, June 16.

National Institutes of Health. 1995. Diabetes in America. Bethesda, MD: National Institutes of Health, National Institute of Diabetes and Digestive and Kidney Diseases.

Ramsey, S., K. H. Summer, S. A. Leong, H. G. Birnbaum, J. E. Kemner, and P. Greenberg. 2002. "Productivity and Medical Costs of Diabetes in a Large Employer Population." Diabetes Care 25 (1): 23-9.

Stata Corporation. 2003. Stata (version 8.0). College Station, TX: Stata Corporation. Vijan, S., T. P. Hofer, and R. A. Hayward. 1997. "Estimated Benefits of Glycemic Control in Microvascular Complications in Type 2 Diabetes.” Annals of Internal Medicine 127 (9): 788-95.

Wingard, D. L., E. L. Barrett-Connor, C. Scheidt-Nave, and J. B. McPhillips. 1993. "Prevalence of Cardiovascular and Renal Complications in Older Adults with Normal or Impaired Glucose Tolerance or NIDDM: A Population-Based Study." Diabetes Care 16 (7): 1022-5. 
1670 